\title{
Results of production tests of the "Hyponat-BPO"
}

\author{
Peter A. Popov*, Irina V. Timofeeva, Svetlana A. Lavina
}

All-Russian Research Institute of Veterinary Sanitation, Hygiene and Ecology - Federal Scientific Center All-Russian Research Institute of Experimental Veterinary Medicine named after K.I. Scriabin and Ya.R. Kovalenko of the Russian Academy of Sciences, Moscow, 123022, Russia

\begin{abstract}
The development of new detergent agents is mainly due to the creation of new compositions of chemical agents, which increases their cost. The article presents the results of production tests of the previously developed disinfection modes for refrigerators "Giponat BPO". As a result of the production tests, it was found that the disinfectant "Hyponat BPO" provides $100 \%$ disinfection of refrigerated chambers, as well as auxiliary equipment at meat processing plants. Thus, it was found that the positive effect of surface disinfection when controlled by a test culture of E. coli was achieved by the use of a $2 \%$ solution with an exposure of 30 minutes, staphylococcus with a $-3 \%$ solution and an exposure of 50 minutes and when controlled by a TMC $-4 \%$ solution and an exposure of 60 minute.
\end{abstract}

\section{Introduction}

Disinfection plays an important role in the complex of measures for the prevention and elimination of infectious diseases of farm animals and birds. Disinfection measures are of particular importance in emergencies of a natural and man-made nature, since they are designed to ensure the reduction and elimination of pathogens that are dangerous for the national economy of the country as soon as possible.

The successful implementation of disinfection measures is determined by the state of the provision of veterinary practice with highly effective drugs and highperformance technical means, their range and compliance with modern requirements [1-4].

The list of traditional detergent agents and disinfectants available for mass consumption (caustic soda, formaldehyde-containing products, chloroactive substances, phenols, quaternary ammonium compounds, etc.) and their choice today remains very limited. In addition, the need for veterinary needs in traditional disinfectants is not fully satisfied and every year their supply is reduced. At the same time, the import and introduction into disinfection practice of the country, although quite effective, but very expensive imported disinfectants, is strongly promoted.

Analyzing the current situation in the country, it is necessary to recognize that the above-mentioned Russian traditional disinfectants are inferior to imported ones in terms of safety and convenience in work, environmental safety and other consumer qualities, but due to significantly lower price, they are still most widely used for the purposes of veterinary disinfection.
The role of disinfection, carried out together with other activities, is one of the factors providing the production of finished products of a high sanitary level. During the production of raw materials with initially low contamination, it is possible to confidently predict the development of microbial contamination during the storage and sale of finished and processed products. One of the main points of contamination is the slaughter of cattle, where contamination occurs through the surface of the slaughter carcass. Therefore, maintaining a low bacterial background in the slaughter rooms, in order to reduce sedimentation contamination, is an urgent task. A high-quality and timely disinfection of premises can provide a low bacterial background.

Meat is a very favorable environment for the development of many microorganisms. It can be infected with pathogenic microorganisms both during the life of an animal (endogenous contamination) and during slaughter, cutting, transportation and storage (exogenous contamination). Therefore, in all cases, it is necessary to observe the sanitary and hygienic rules for the storage and transportation of meat.

In order to preserve the quality, meat is processed by various types, such as cold storage, salting, drying and others. This changes the microflora of meat. If the storage conditions are violated, meat and meat products quickly undergo microbial contamination and often cause microbial food poisoning. Such as salmonellosis caused by bacteria of the genus Salmonella, toxic infections caused by bacteria of the genus Proteus, E. Coli, botulism caused by meat products contaminated with Clostridium botulinum toxin and many other pathogens that are dangerous for both animals and humans. Even a short-term exposure of products to the air with pathogenic or opportunistic bacteria is quite

\footnotetext{
*Corresponding author: popov.petr18@gmail.com
} 
enough to the development of infection, according to the data of microbiological air monitoring. [5-11]

One of the most important sources of the contamination of meat during storage is the sedimentation of microorganisms on the surface of the carcass during storage. This can be prevented by highquality disinfection of industrial premises and refrigerating chambers [3.5].

Currently in the Russian Federation, more than 400 stable chemicals, both domestic and imported, containing chlorine, hydrogen peroxide, formaldehyde, QAS, acids, alkalis, colloidal forms of metals, essential oils, etc. are used for disinfection of objects of veterinary supervision. These disinfectants can be highly volatile, toxic and environmentally unfriendly. They also can leave residual contents in processed products or have a high cost of use [12].

The first hypochlorite solutions were known more than 230 years ago and the methods of their production have hardly changed to this day. Only the automation of the production process improved. The French chemist Claude Louis Berthollet can be considered as the founder of the production of hypochlorites. In 1785 he discovered that the resulting solution had bleaching properties passing chlorine through water. However the solution turned out to be extremely unstable, since it was hypochlorous acid, and in 1787 the product was modified by the Englishman Leonard Alban by replacing water with a solution of caustic potash, or potassium hydroxide $(\mathrm{KOH})$, as a result of which a solution of potassium hypochlorite $(\mathrm{KClO})$ was obtained. This substance was named Eau de Javelle (translated from French as "bleach", "jelly water") and was mainly used for bleaching fabrics.

In addition the preparations based on sodium hypochlorite, obtained both by electrochemical and classical chemical methods, have become widespread in veterinary medicine and medical practice. These drugs have both positive characteristic such as low toxicity, a wide antimicrobial spectrum of action, low corrosive activity and negative ones such as instability of the active chlorine content during storage of drugs.

Thus, the development of new highly effective, cheap and multifunctional, as well as environmentally friendly disinfectants is an important and priority area of research in the field of veterinary sanitation [13-14].

The history of the use of sodium hypochlorite as a disinfectant dates back to World War I, when chemically obtained sodium hypochlorite was used to irrigate wounds. I. Bunyan first used $0.25 \%$ sodium hypochlorite solution during World War II to irrigate burn wounds, followed by the application of an occlusive dressing moistened with $0.05 \%$ sodium hypochlorite solution. This solution was used quite actively, right up to the era of antibiotics. With the discovery of antibiotics, interest in this agent has dropped significantly [12-14].

In foreign countries the industry produces a number of sodium hypochlorite solutions for external use in various concentrations with the addition of stabilizers and having their own name depending on the country of origin, for example: $0.4-0.5 \%$ "Deikin" solution
(France), $1 \%$ "Milton" solution (England), 5.25\% "Clorox" solution (USA), etc. [2, 3].

The first reports on the use of sodium hypochlorite in Russia were made at the conference "Electrochemical Methods in Medicine" in Dagomys in 1991 [3-5].

Accumulating the experience with the use of sodium hypochlorite, it was found that the drug is effective against most common microorganisms, including antibiotic-resistant ones. According to research data, sodium hypochlorite is formed in the body and naturally in phagocytic cells during the deactivation of the foreign pathogen captured by them. The effect of the "related substance" allows explaining both the high efficiency of the sodium hypochlorite solution and its good tolerance by the body [8].

Sodium hypochlorite is an oxygen carrier and therefore a strong oxidizing agent.

It is necessary to note that lipid peroxidation is activated (experiment), which may lead to the increase in intoxication due to the toxicity of lipid peroxidation products. However, this is not observed in clinical practice, since the products of peroxidation themselves, in particular malondialdehyde, apparently undergo $\mathrm{OCl}$ inactivation, which leads to a decrease in its content.

The studies of a number of authors show a pronounced antimicrobial effect of sodium hypochlorite against gram-negative and gram-positive microorganisms. Many researchers associate the mechanism of antimicrobial action of sodium hypochlorite with the oxidation of sulfhydryl groups in enzymes with the help of chlorine. Sodium hypochlorite solutions prepared on the EDO-4 apparatus surpass other studied forms of drugs with oxidizing properties in their antimicrobial action [3-8].

The bactericidal effect of the drug is reasoned by the destruction of the microbial cell wall with the release of cytoplasmic contents [9].

Sodium hypochlorite also has antifungal and antiviral effects. It is found that it inactivates the human immunodeficiency virus (HIV). Therefore it is a standard hospital disinfectant for medical instruments and surfaces contaminated with HIV [6.9].

The research of a group of authors showed the hyposensitizing and immunomodulatory effects of sodium hypochlorite on the function of immunocompetent cells. The immune stimulating effect in low concentrations of sodium hypochlorite $(300 \mathrm{mg} /$ 1) and immunosuppressive effect at concentrations over $600 \mathrm{mg} / \mathrm{l}$ are established.

Modern veterinary medicine has a relatively small number of detoxifying drugs and it is necessary to note that the majority of researchers recognize the death of young animals with gastrointestinal diseases from severe intoxication and exsicosis. Consequently, the search for detoxifying agents and the development of new methods of treatment on their basis is of both scientific and practical interest $[5,14]$.

In this regard, the studied issue seems to be important and the search for new highly effective and inexpensive detoxification agents used in the complex treatment of young animals can significantly increase the 
effectiveness of therapeutic measures and reduce mortality [9].

The widespread use of sodium hypochlorite for the prevention of diseases and the treatment of farm animals was preceded by the studies on laboratory animals (guinea pigs) in order to determine the harmlessness of this drug. The experience showed that the use of sodium hypochlorite in concentrations from 370 to $560 \mathrm{mg} / 1$ does not cause significant changes in the clinical state of laboratory animals and negative morphohistological reactions on the part of organs in contact with the drug during its administration.

\section{Materials and methods}

A multicomponent disinfectant based on sodium hypochlorite "Hyponat BPO" was tested in production conditions. Such components as sodium hypochlorite of grade "A", calcium hypochlorite, lithium hypochlorite, alkyldimethylbenzylammonium chloride, its commercial form catamine $\mathrm{AB}$, containing $50 \%$ of the basic substance and technical caustic soda were used for the development of a disinfectant. This production method mixing the components and using the veterinary practice was patented.

The objects of processing were refrigerating chambers for temporary storage of chilled meat (pork) of Prodtorg +, the Podolsk district, the Moscow region.

The study of the disinfectant properties of the multicomponent product based on sodium hypochlorite "Hyponat BPO" was carried out in accordance with the Methodological Instructions on the Procedure for Testing New Disinfectants for Veterinary Practice" (M., 1987) and the "Guidance R 4.2.2643-10. Methods of laboratory research and testing of disinfectants to assess their effectiveness and safety" (Official edition, M., 2011)

During the tests in production conditions, the quality of disinfection was controlled by the release of bacteria of the E. coli group, staphylococci and by the total microbial count (TMC) from washes from naturally contaminated surfaces of premises in accordance with the requirements of the "Rules for Disinfection and Disinfestation of Objects of State Veterinary Surveillance" (2002). The washes from surfaces taken before disinfection served as control ones. The effectiveness of disinfection was estimated by the presence or absence of growth of the corresponding microorganisms after the treatment.

The quality control of disinfection was carried out by the examination of the washings before and after treatment. In order to isolate Escherichia coli, nutrient CODA media were used, staphylococcus - $6.5 \%$ saline beef-extract broth and $8.5 \%$ saline beef-extract agar, and for the determination of TMC - beef-extract agar. The final registration of the results of the inoculation was carried out after 7-14 days.

\section{Research results}

Earlier, in the laboratory of veterinary and sanitary examination of All-Russian Research Institute of Veterinary Sanitation, Hygiene and Ecology - Federal Scientific Center All-Russian Research Institute of Experimental Veterinary Medicine named after K.I. Scriabin and Ya.R. Kovalenko of the Russian Academy of Sciences the research was conducted on the development of the drug "Hyponat-BPO". In addition, the bactericidal and bacteriostatic action in relation to vegetative and spore forms of microorganisms was determined and the phenolic index and corrosive activity were studied.

In the first series of experiments, the studies were carried out to determine the microbial contamination of refrigerated chambers at the meat processing enterprises of Prodtorg + , the Moscow region (Table 1).

Table 1. Indicators of bacterial contamination of slaughter and primary processing workshops at a meat processing plant $(\mathrm{n}=3)$

\begin{tabular}{|c|c|c|c|c|}
\hline \multirow[t]{2}{*}{ № } & \multirow[t]{2}{*}{ Sampling location } & total microbial count & E.coli & St. aureus \\
\hline & & \multicolumn{3}{|c|}{$C F U / 100 \mathrm{~cm}^{2}$} \\
\hline \multicolumn{5}{|c|}{ 1. Bacterial contamination of refrigerating surfaces of chamber No. 1} \\
\hline 1 & Floor & $100 * 10^{2}$ & $30 * 10^{2}$ & $48 \pm 3$ \\
\hline 2 & Wall & $60 * 10^{2}$ & $25 * 10^{2}$ & $12 \pm 2$ \\
\hline \multicolumn{5}{|c|}{ 2. Bacterial contamination of refrigerating surfaces of chamber No. 2} \\
\hline 1 & Floor & $25 * 10^{2}$ & 0 & $12 \pm 1$ \\
\hline 2 & Wall & $63 * 10^{2}$ & $35 * 10^{2}$ & $21 \pm 2$ \\
\hline \multicolumn{5}{|c|}{ 3. Bacterial contamination of refrigerating surfaces of chamber No. 3} \\
\hline 1 & Floor & $89 * 10^{2}$ & $26^{*} 10^{2}$ & $12 \pm 2$ \\
\hline 2 & Wall & $42 * 10^{2}$ & $19 * 10^{2}$ & $8 \pm 2$ \\
\hline
\end{tabular}

$\mathrm{P}>0,001$

According to Table 1 the refrigerated chambers had significant contamination with vegetative microflora and total microbial numbers. Moreover single colonies of mold fungi were identified. These studies allowed analyzing microbial contamination and carrying out production tests of the modes of application of the "Hyponat BP" agent developed in laboratory conditions.

The results of the production tests carried out are presented in tables 2-4. 
Table 2. Experimental results on the use of a multicomponent disinfectant based on sodium hypochlorite under control of E. coli

\begin{tabular}{|c|c|c|c|c|}
\hline \multirow{2}{*}{$\begin{array}{c}\text { Drug } \\
\text { concentration, } \%\end{array}$} & 10 & 20 & 30 & 40 \\
\hline 0,5 & + & + & + & + \\
\hline 1,0 & + & + & - & + \\
\hline 2,0 & + & + & - & - \\
\hline 3,0 & + & - & - & - \\
\hline
\end{tabular}

Note: (-) - lack of growth; (+) - growth

Table 3. Experimental results on the use of a multicomponent disinfectant based on sodium hypochlorite under staphylococcus control

\begin{tabular}{|c|c|c|c|c|c|}
\hline \multirow{2}{*}{$\begin{array}{c}\text { Drug } \\
\text { concentration, } \%\end{array}$} & \multicolumn{5}{|c|}{ Exposure, min. } \\
\cline { 2 - 6 } & 20 & 30 & 40 & 50 & 60 \\
\hline 1,0 & + & + & + & + & + \\
\hline 2,0 & + & + & + & + & + \\
\hline 3,0 & + & + & - & - & - \\
\hline 4,0 & + & + & + & - \\
\hline
\end{tabular}

Note: (-) - lack of growth; (+) - growth

Table 4. Experimental results on the use of a multicomponent disinfectant based on sodium hypochlorite under control by TMC

\begin{tabular}{|c|c|c|c|c|c|}
\hline \multirow{2}{*}{$\begin{array}{c}\text { Drug } \\
\text { concentration, } \%\end{array}$} & 30 & 40 & 50 & 60 & 70 \\
\hline & + & + & + & + & + \\
\hline 2,0 & + & + & + & + & + \\
\hline 3,0 & + & + & + & - & - \\
\hline 5,0 & + & + & - & - & - \\
\hline
\end{tabular}

Note: (-) - lack of growth; (+) - growth

The disinfection of refrigerated chambers is achieved:

- when controlling the quality of disinfection for the release of E. coli, the surfaces of the floor and walls of the refrigerator trailer were disinfected by a single application of a $2.0 \%$ solution (according to the preparation) of a hypochlorite-based agent at a consumption rate of $0.25-0.51 / \mathrm{m}^{2}$ and an exposure time of 30 minutes (Table 2.)

- when controlling the quality of disinfection for the release of staphylococci, the disinfection of the surfaces of the floor and walls of the refrigerator trailer was disinfected by a single application of a $3.0 \%$ solution (for the preparation) of the "Hyponat BPO" agent at a consumption rate of $0.25-0.51 / \mathrm{m}^{2}$ and an exposure of 50 minutes (Table 3 ).

- when controlling the quality of disinfection for the release of TMC, the disinfection of the surfaces of the floor and walls of the refrigerated trailer was disinfected by a single application of a $4.0 \%$ solution (according to the preparation) of the "Hyponat BPO" agent at a consumption rate of $0.25-0.51 / \mathrm{m}^{2}$ and an exposure of 60 minutes (Table 4).

In control washes from the surfaces of the chambers (after cleaning and washing), E. coli was found in $85 \%$, and staphylococcus - in $100 \%$ of the samples.

\section{Conclusion}

During this research we studied the microbial contamination of refrigerated chambers of a meatprocessing enterprise. It was found that the disinfectant "Hyponat BPO" had high activity against gram-positive and gram-negative vegetative forms of bacteria and with respect to the total microbial count, allowing effective current disinfection. According to the results of the experiments, the "Hyponat BPO" agent can be recommended for preventive disinfection of veterinary inspection objects, in particular, refrigerated chambers at meat processing plants.

\section{References}

1. M.P. Butko, The use of a composite disinfectant based on sodium hypochlorite in the treatment of refrigeration chambers in the meat-processing industry, Problems of veterinary sanitation, hygiene and ecology, 2(12), 6-10 (2014)

2. M.P. Butko, A new direction in the production of biocides and their applied value, Problems of veterinary sanitation, hygiene and ecology, 1(29), 39-44 (2019)

3. E.S. Lutsenko, Practical Aspects of Choosing Modern Disinfectants in a Multidisciplinary Medical

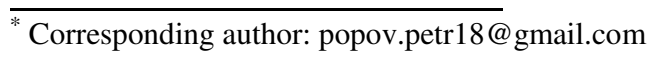


Institution, Profession: Theory and Practice (Moscow), 1, 30-31 (2008)

4. M.S. Saypullaev, Production tests of the disinfectant Teotropin R +, Veterinary of agricultural animals, 2 , 32-34 (2013)

5. M.S. Saypullaev, Disinfection efficiency of solutions of the drug "Dezakar", Problems of veterinary sanitation, hygiene and ecology, 2(8), 3034 (2012)

6. M.S. Saypullaev, S.Sh. Kabardiev, K.A. Karpushchenko, A.U. Koichuev, Acute and subacute toxicity of solutions of the drug "Mixamin", Problems of veterinary sanitation, hygiene, ecology, 1(10), 54-55 (2013)

7. M.S. Saypullaev, S.Sh. Kabardiev, A.U. Koichuev, Study of the acute and subacute toxicity of the drug "Dezakar", Veterinarian, 2, 24-26 (2012)

8. N.G. Romanenko, A. Yu. Eldyshev, A method for increasing the efficiency of electrolysis plants in a group water supply system of the Liman district by using hydrogen technologies, Bulletin of the Astrakhan State Technical University, 1(65), 55-65 (2018)

9. P.A. Popov, M.P. Butko, Technology of ozone application for disinfection of vehicles used for transportation of animal products, Problems of veterinary sanitation, hygiene and ecology, 2(18), 38-45 (2016)

10. N.I. Popov, D.I. Udavliev, N.V. Shuteeva, Study of the effectiveness of the drug "Iodez" in a composition with modern insectoacaricidal preparations for the simultaneous disinfection and deacarization of pig-breeding premises, Problems of veterinary sanitation, hygiene and ecology, 1(9), 2325 (2013)

11. N.I. Popov, STEP - a new foaming disinfectant for veterinary medicine, Problems of veterinary sanitation and ecology. Abstracts of the International Scientific Conference, 72 (1999)

12. N.I. Popov, G. D. Volkovsky, N.V. Griganova, S.A. Michko, Achievements of research and development in the field of disinfection, Problems of veterinary sanitation and ecology. Collection of scientific works, All-Russian Research Institute of Veterinary Sanitation, Hygiene and Ecology, 117, 39-47 (2005)

13. N.I. Popov, G. D. Volkovsky, N.V. Griganova, S.A. Michko, D.I. Udavliev, Results of tests of the drug PVK, Veterinary, 5, 10 (2001)

14. V.M. Bakhir, Spectrum of application possibilities of electrochemically activated anolytes from STEL devices of different modifications and generations, Medical Alphabet, 2, 42-48 (2010) 